\title{
Motion-Preserving Navigated Primary Internal Fixation of Unstable C1 Fractures
}

\author{
Shanmuganathan Rajasekaran, Dilip Chand Raja Soundararajan, Ajoy Prasad Shetty, Rishi Mugesh Kanna \\ Department of Spine Surgery, Ganga Hospital, Coimbatore, India
}

\section{Study Design: Prospective observational study.}

Purpose: To assess the safety, efficacy, and benefits of computed tomography (CT)-guided C1 fracture fixation.

Overview of Literature: The surgical management of unstable C1 injuries by occipitocervical and atlantoaxial (AA) fusion compromises motion and function. Monosegmental $\mathrm{C1}$ osteosynthesis negates these drawbacks and provides excellent functional outcomes. Methods: The patients were positioned in a prone position, and cranial traction was applied using Mayfield tongs to restore the CO$\mathrm{C} 2$ height and obtain a reduction in the displaced fracture fragments. An intraoperative, CT-based navigation system was used to enable the optimal placement of $\mathrm{C} 1$ screws. A transverse rod was then placed connecting the two screws, and controlled compression was applied across the fixation. The patients were prospectively evaluated in terms of their clinical, functional, and radiological outcomes, with a minimal follow-up of 2 years.

Results: A total of 10 screws were placed in five patients, with a mean follow-up of 40.8 months. The mean duration of surgery was $77 \pm 13.96$ minutes, and the average blood loss was $84.4 \pm 8.04 \mathrm{~mL}$. The mean combined lateral mass dislocation at presentation was $14.6 \pm 1.34 \mathrm{~mm}$ and following surgery, it was $5.2 \pm 1.64 \mathrm{~mm}$, with a correction of $9.4 \pm 2.3 \mathrm{~mm}(p<0.001)$. The follow-up CT showed excellent placement of screws and sound healing. There were no complications and instances of AA instability. The clinical range of movement at 2 years in degrees was as follows: rotation to the right $\left(73.6^{\circ} \pm 9.09^{\circ}\right)$, rotation to the left $\left(71.6^{\circ} \pm 5.59^{\circ}\right)$, flexion $\left(35.4^{\circ} \pm 4.5^{\circ}\right)$, extension $\left(43.8^{\circ} \pm 8.19^{\circ}\right)$, and lateral bending on the right $\left(28.4^{\circ} \pm 10.45^{\circ}\right)$ and left $\left(24.8^{\circ} \pm 11.77^{\circ}\right)$. Significant improvement was observed in the functional Neck Disability Index from $78 \pm 4.4$ to $1.6 \pm 1$.6. All patients returned to their occupation within 3 months.

Conclusions: Successful $\mathrm{C} 1$ reduction and fixation allows a motion-preserving option in unstable atlas fractures. CT navigation permits accurate and adequate monosegmental fixation with excellent clinical and radiological outcomes, and all patients in this study returned to their preoperative functional status.

Keywords: Atlas; Injury; Internal fixation; Atlanto-axial fusion; Minimally invasive surgical procedures

\section{Introduction}

The reported incidence of atlas fractures ranges from
$2 \%$ to $13 \%$ of all cervical spine injuries and constitutes around $1 \%-2 \%$ of all spine injuries [1]. Isolated unstable atlas fractures (UAF) are rare spinal injuries in which ap-

This is the 2019 APSS-Asian Spine Journal Best Paper Award.

Received Jun 10, 2019; Revised Oct 5, 2019; Accepted Oct 6, 2019

Corresponding author: Shanmuganathan Rajasekaran

Department of Spine Surgery, Ganga Hospital, 313, Mettupalayam Road, Coimbatore-641043, Tamil Nadu, India

Tel: +91-9843022325, Fax: +91-422-4383863, E-mail: rajasekaran.orth@gmail.com 
proximately $77 \%$ of $\mathrm{C} 1$ fractures are associated with other cervical vertebral injuries, especially axis (C2) followed by the subaxial cervical spine [2]. Long-term studies on conservative management have predicted poor outcomes in these UAF $[3,4]$. The long immobilization period and unpredictable healing of bones and ligaments, leading to persistent pain and instability, in those managed conservatively has resulted in an evolution from conservative measures to surgical treatment. The standard surgical options of occipitocervical (OC) fusion and atlantoaxial (AA) fusion would undoubtedly resolve the issue of instability, but at the cost of atlanto-occipital (AO) and AA joint mobility. A reduction of $50 \%$ in cervical sagittal and rotational movements compromises postoperative functional status and vocational performance [5]. The ideal treatment for UAF would be to restore the $\mathrm{C} 0-\mathrm{C} 2$ height and articular incongruity of $\mathrm{AO}$ and $\mathrm{AA}$ joints, reduce the lateral mass displacement to a near anatomical position, and maintain the mobility of these joints.

Isolated $\mathrm{C} 1$ osteosynthesis is an effective alternative strategy, whereby a monosegmental fixation provides stability as well as mobility in UAF [6]. However, the complex and variable anatomy of the craniocervical junction, alteration in surgical landmarks following trauma, and the excessive displacement along with the movement of the lateral mass during instrumentation preclude the safe placement of screws in this intricate fixation. A malposition of screws causes postoperative pain and may lead to a failure of the overall construct, requiring revision surgery [7]. The navigated monosegmental osteosynthesis of the C1 fracture may negate these complications and achieve significant clinical and radiological outcomes. To our knowledge, there are no studies that have evaluated the safety and efficacy of navigated $\mathrm{C} 1$ fixations in this monosegmental construct. We describe our successful management of five UAF injuries using an AIRO computed tomography (CT) scanner (Brainlab AG, Feldkirchen, Germany) navigated $\mathrm{C} 1$ lateral mass screw fixation and transverse compression osteosynthesis, and review other methods reported in the literature.

\section{Materials and Methods}

This study was performed after obtaining approval from the Institutional Review Board of the Ganga Medical Center and Hospitals Pvt. Ltd. (IRB approval no., 2014-13), and informed consent was obtained from all participants. All ethics pertaining to the Helsinki declaration were followed.

\section{Study design}

A prospective observational and interventional study was performed that examined five cases of isolated UAF. Only patients with an intact neurological status and a normal Glasgow Coma Scale score of 15 were included in the study; patients with other skeletal and systemic injuries (such as to the head, chest, or abdomen) were excluded. The surgeries were performed by a single surgeon in a single institution.

\section{Procedure}

The surgical workflow (Fig. 1) in a typical case of UAF
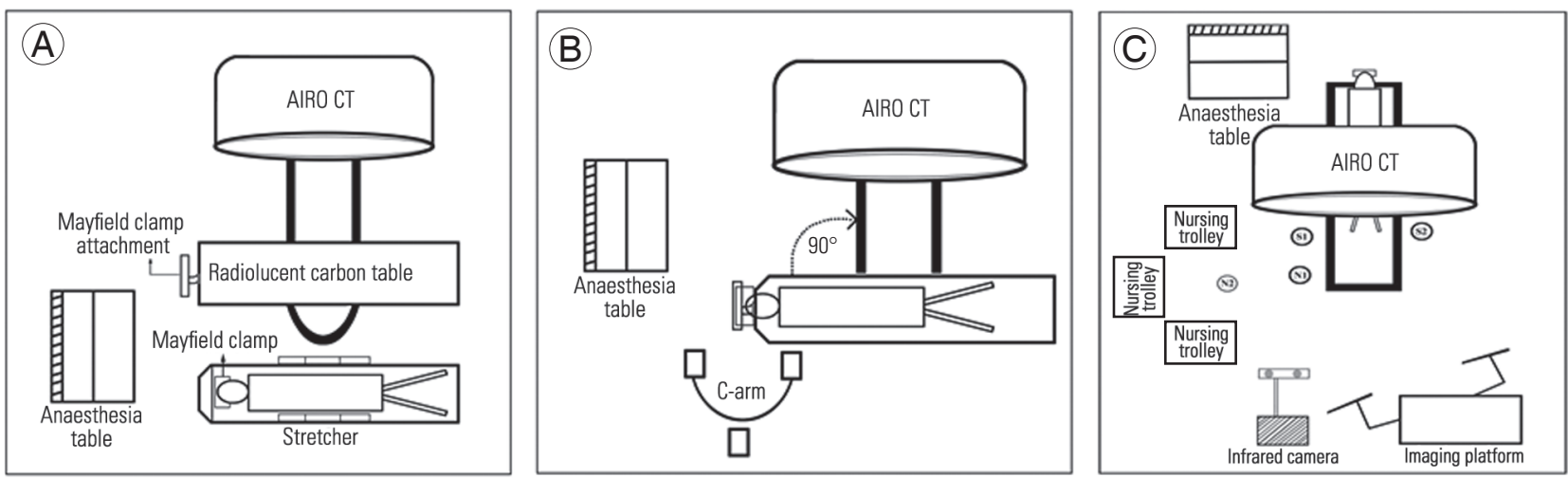

Fig. 1. (A) The operating room setup, showing the initial position of the patient supine on a stretcher during the intubation and placement of the Mayfield clamps; (B) the turning-over of the patient to a prone position on a radioluscent table, with a C-arm to mark the skin levels before surgical incision; and (C) after exposure of the surgical field, the patient is seen undergoing intraoperative CT scan. CT, computed tomography. 
(Fig. 2) has been depicted. AIRO CT scanner (Brainlab AG) device was first positioned in the operating suite, and the portable radiolucent carbon fiber CT table attached to it. The table was then turned $90^{\circ}$ anti-clockwise and placed perpendicular to the CT gantry. Thereafter, the patient was shifted to the operating room in a mobile operating room stretcher trolley and positioned parallel to the radiolucent table. Using standard techniques, the patients were anesthetized and intubated on the trolley. The surgeon placed the Mayfield clamp over the skull under general anesthesia, and care was taken to avoid injury to the neurovascular structures during application. This was followed by the turning-over procedure to position the patients prone on the radiolucent table, with the head held with the Mayfield clamp. The table was then rotated $90^{\circ}$ clockwise and kept in line with the ICT gantry. Cranial traction was then applied with the Mayfield tongs to restore the $\mathrm{C} 0-\mathrm{C} 2$ height, which is necessary to restore the functional stability of the intact vertically oriented ligaments and reduce fracture displacement.

After minimal standard midline posterior surgical exposure, a meticulous dissection was performed to expose the posterior arch of $\mathrm{C} 1$ so as to avoid bleeding from the venous plexus. Using a blunt periosteal elevator, the inferior surface of $\mathrm{C} 1$ was exposed up to the junction of the lateral mass and arch. A minimally invasive reference array was attached to the cranial portion of the $\mathrm{C} 2$ spinous process. Using a mobile intraoperative AIRO CT scanner (Brainlab AG) and infrared tracking camera with image guidance system (BrainLab CurveTM, Brainlab AG), the optimal entry points were determined by the placement of the navigation probe, and with a high-speed 2-mm Midas Rex Legend (Medtronic, Fort Worth, TX, USA) motorized burr, the entry points were marked and created on both sides. Motorized drill bits were then used to create trajectories along the planned direction. Handheld devices were avoided to prevent wobbling and motionrelated artifacts. Fig. 3 shows the planning of the screw trajectories, control ICT, and postoperative radiographs. After reconfirming the established paths with the navigation probe, 3.5-mm-diameter polyaxial screws of variable length were inserted bilaterally into the $\mathrm{C} 1$ lateral mass, and a pre-bent titanium transverse rod was placed across the screws. Controlled compression was applied across the fixation to obtain further reduction, and direct intraoperative control CT and postoperative radiographs were taken and checked for adequacy. Following surgery, the patients were discharged on the third postoperative day, and immobilized with a rigid cervical collar for 6 weeks. The rigid mobilization provided in this series was done to ensure adequate soft tissue healing, before the start of a structured rehabilitation program.

\section{Outcome and follow-up}

The clinical, functional, and radiological findings were evaluated periodically. Patients were allowed to engage in normal activities after ruling out instability at 3 months by the absence of AA displacement in flexion-extension dynamic lateral cervical radiographs. At 1 year, a CT was taken to assess healing, as shown in Fig. 4.
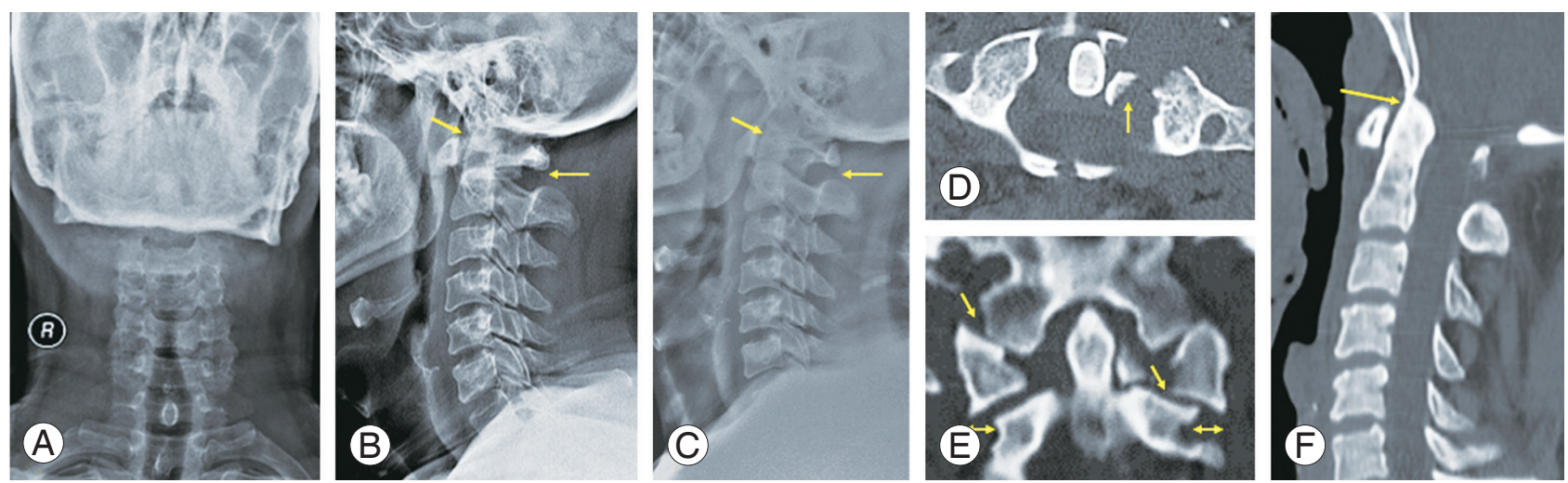

Fig. 2. (A) An inadequate open-mouth anteroposterior view; (B) lateral cervical radiographs demonstrating a disruption to the spino-laminar line posteriorly, and an increase in anterior atlanto-dens interval (arrows); (C) a traction radiograph demonstrating reduction (arrows); (D) an axial CT showing disruption to the anterior and posterior arch, along with a fracture in the lateral mass and avulsion of the transverse atlantal ligament, suggesting instability (arrow); (E) a coronal CT shows the disruption of the atlantoaxial and atlanto-occipital joints with a combined lateral mass dislocation of $12 \mathrm{~mm}$, further suggesting instability (arrows); and (F) the sagittal image shows cranial settling, due to a reduction in the C0-C2 height (arrow). CT, computed tomography. 

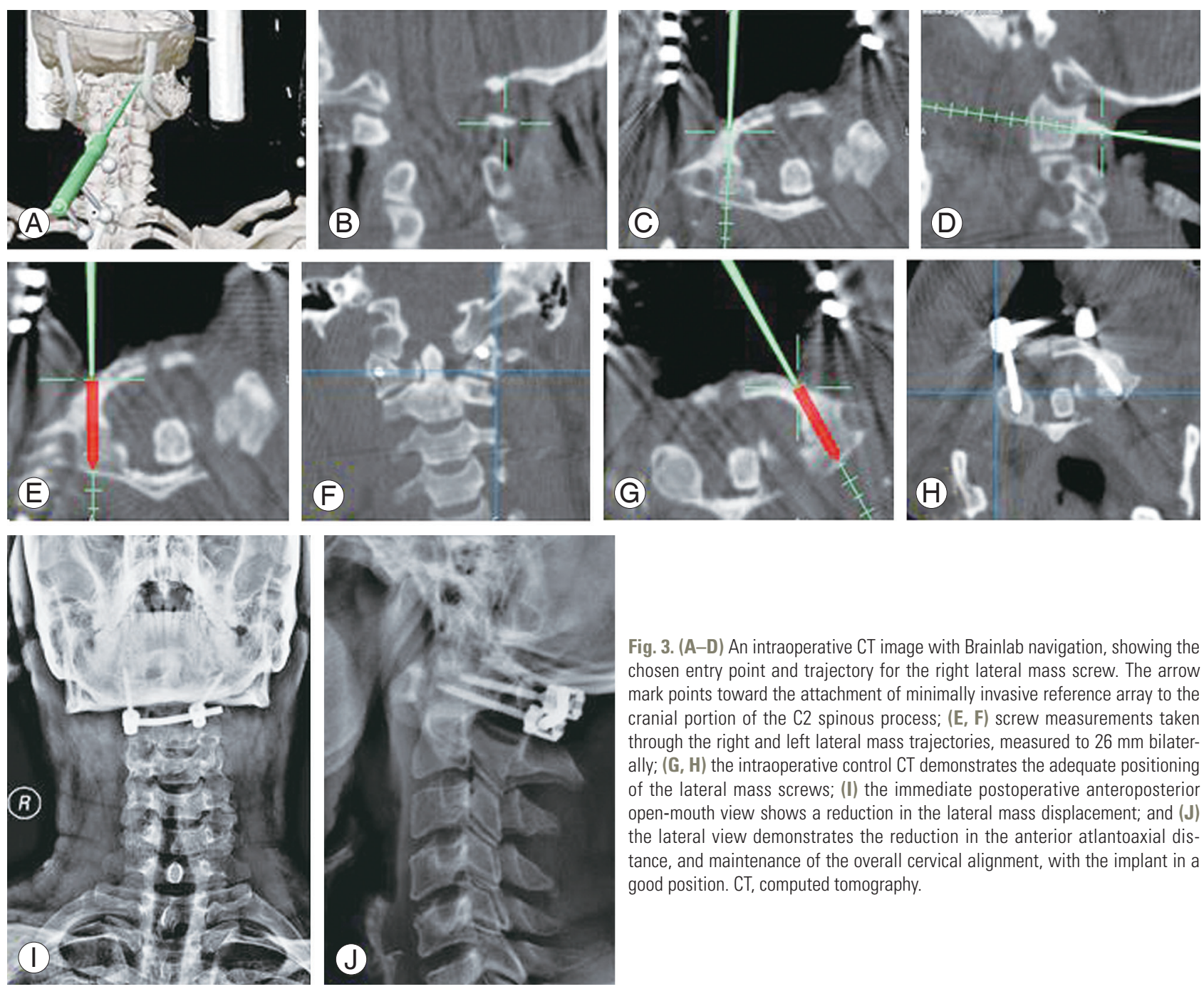

Fig. 3. (A-D) An intraoperative CT image with Brainlab navigation, showing the chosen entry point and trajectory for the right lateral mass screw. The arrow mark points toward the attachment of minimally invasive reference array to the cranial portion of the $\mathrm{C} 2$ spinous process; $(\mathbf{E}, \mathrm{F})$ screw measurements taken through the right and left lateral mass trajectories, measured to $26 \mathrm{~mm}$ bilaterally; $(\mathbf{G}, \mathbf{H})$ the intraoperative control $\mathrm{CT}$ demonstrates the adequate positioning of the lateral mass screws; (I) the immediate postoperative anteroposterior open-mouth view shows a reduction in the lateral mass displacement; and (J) the lateral view demonstrates the reduction in the anterior atlantoaxial distance, and maintenance of the overall cervical alignment, with the implant in a good position. CT, computed tomography.
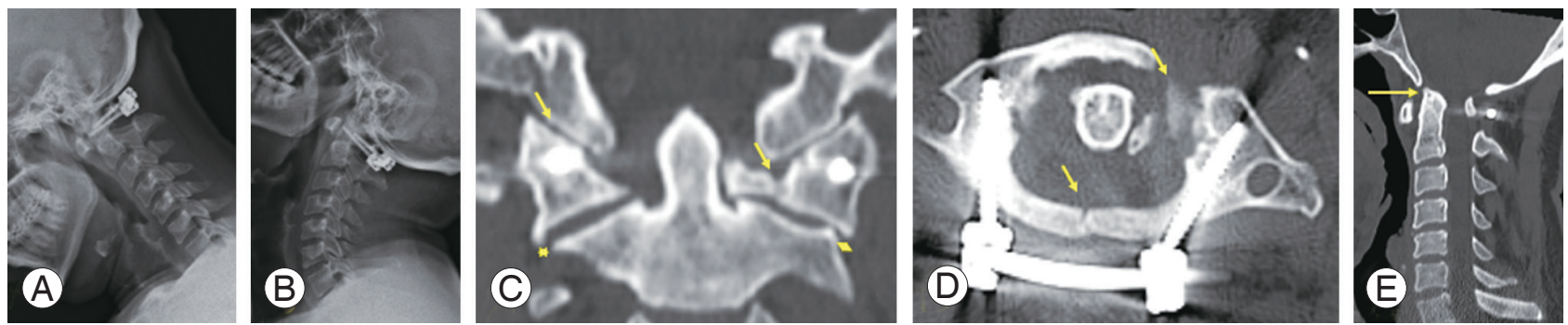

Fig. 4. (A, B) The dynamic flexion and extension radiograph shows no signs of instability at 6 months; (C) the coronal CT shows good articular congruity of the atlantooccipital and atlantoaxial joints, while the combined lateral mass dislocation was only $3 \mathrm{~mm}$, and shows bridging at the avulsion site (arrows); (D) the axial CT with optimal placement of the $\mathrm{C} 1$ lateral mass screws, the complete healing of the posterior arch fracture, and the osseous bridging anteriorly indicate the complete healing of the fracture (arrows); and (E) the sagittal CT shows no evidence of cranial settling (arrow). CT, computed tomography.

\section{Results}

A total of 10 screws were placed in five patients, and the demographic characteristics are listed in Table 1. The mean duration of surgery was $77 \pm 13.96$ minutes, while the average blood loss was $84.4 \pm 8.04 \mathrm{~mL}$. The average screw lengths used were $26.8 \pm 1.78 \mathrm{~mm}$, and the mean screw insertion time on the right-and left-hand sides was $482.2 \pm 24.29$ and $421.6 \pm 9.31$ seconds, respectively. The average follow-up period was 40.8 months (range, 25-59 months). The mean combined lateral mass dislocation (CLMD) at presentation was $14.6 \pm 1.34 \mathrm{~mm}$, and fol- 
Table 1. Demographic and surgical variables

\begin{tabular}{|c|c|c|c|c|c|c|c|c|c|c|}
\hline \multirow[t]{2}{*}{ No. } & \multirow{2}{*}{$\begin{array}{l}\text { Age } \\
\text { (yr) }\end{array}$} & \multirow{2}{*}{ Occupation } & \multirow{2}{*}{ Mechanism of injury } & \multirow{2}{*}{$\begin{array}{l}\text { Follow-up } \\
\text { period (mo) }\end{array}$} & \multirow{2}{*}{$\begin{array}{l}\text { Duration of } \\
\text { surgery (min) }\end{array}$} & \multirow{2}{*}{$\begin{array}{l}\text { Blood loss } \\
\text { (mL) }\end{array}$} & \multicolumn{2}{|c|}{$\begin{array}{c}\text { Screw length } \\
(\mathrm{mm})\end{array}$} & \multicolumn{2}{|c|}{$\begin{array}{l}\text { Screw insertion in } \\
\text { length (sec) }\end{array}$} \\
\hline & & & & & & & Right & Left & Right & Left \\
\hline 1 & 35 & Bus driver & Road traffic accident & 59 & 96 & 84 & 28 & 28 & 482 & 434 \\
\hline 2 & 45 & Cook & Road traffic accident & 48 & 84 & 88 & 24 & 24 & 456 & 420 \\
\hline 3 & 55 & Farmer & Fall from height & 37 & 78 & 94 & 28 & 28 & 475 & 414 \\
\hline 4 & 25 & Cab driver & Road traffic accident & 35 & 65 & 84 & 26 & 26 & 522 & 428 \\
\hline 5 & 38 & Bus driver & Road traffic accident & 25 & 62 & 72 & 28 & 28 & 476 & 412 \\
\hline
\end{tabular}
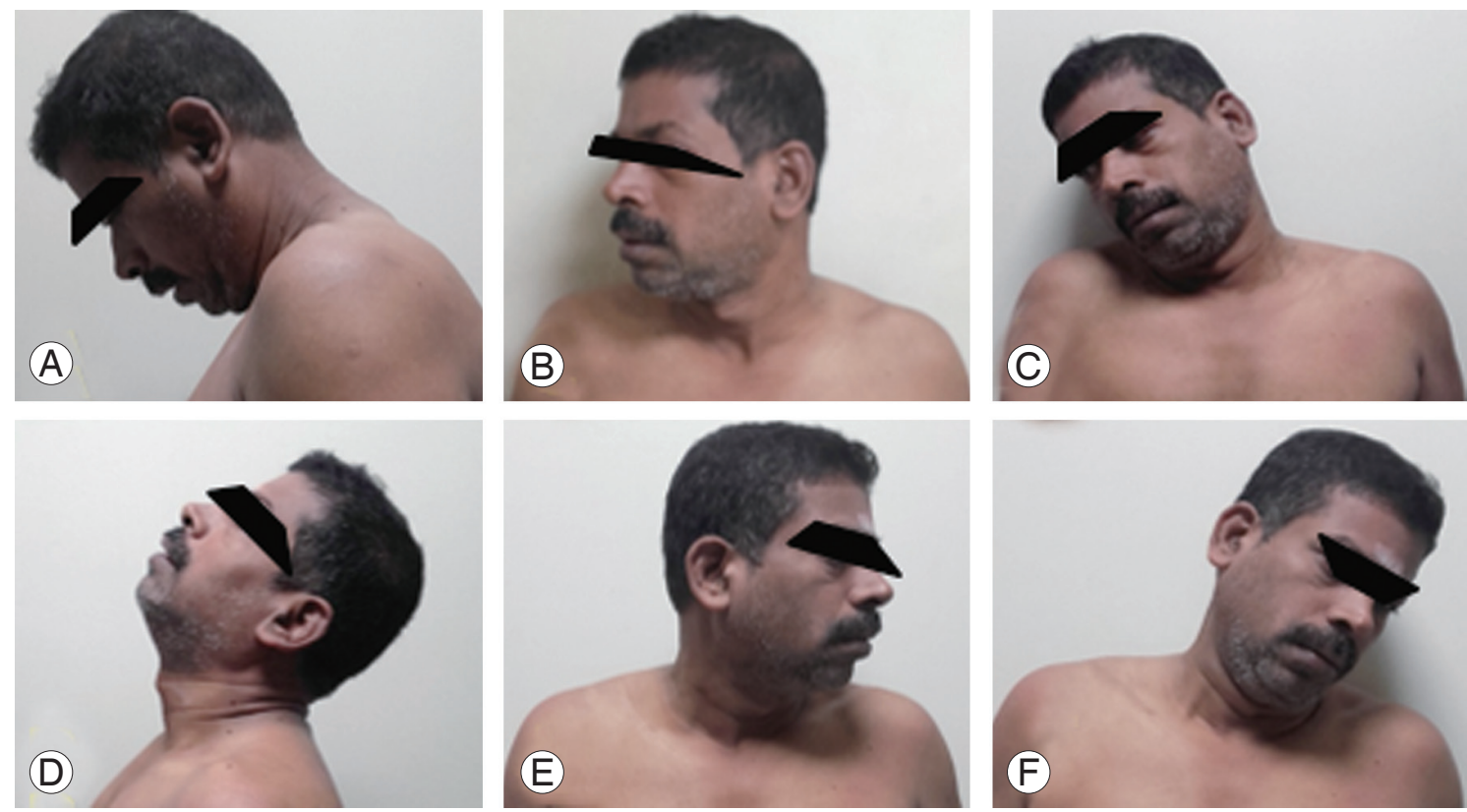

Fig. 5. (A, B) the clinical picture of the patient shows the arc of movement (flexion $=40^{\circ}$ and extension $\left.=50^{\circ}\right),(\mathrm{C}, \mathrm{D})$ the axial rotation of $80^{\circ}$ to the right and $78^{\circ}$ on the left; and (E, F) the right and left lateral bending of $40^{\circ}$ and $35^{\circ}$. The patient provided written informed consent for publication of clinical details and images.

lowing surgery, it was $5.2 \pm 1.64 \mathrm{~mm}$, with a significant correction of $9.4 \pm 2.3 \mathrm{~mm}(p<0.001)$. The follow-up CT revealed the excellent placement of the screws and good healing, with no instances of a transverse foramen breach. The complete restoration of the $\mathrm{C} 0-\mathrm{C} 2$ height and maintenance of the $\mathrm{C} 0-\mathrm{C} 1$ and $\mathrm{C} 1-\mathrm{C} 2$ joint congruity were noted, and there were no complications and instances of AA instability. The clinical ranges of movement at 2 years in degrees were: rotation to the right $\left(73.6^{\circ} \pm 9.09^{\circ}\right)$, rotation to the left $\left(71.6^{\circ} \pm 5.59^{\circ}\right)$, flexion $\left(35.4^{\circ} \pm 4.5^{\circ}\right)$, extension $\left(43.8^{\circ} \pm 8.19^{\circ}\right)$, and lateral bending to the right $\left(28.4^{\circ} \pm 10.45^{\circ}\right)$ and to the left $\left(24.8^{\circ} \pm 11.77^{\circ}\right)$. Fig. 5 shows a normal clinical cervical range of movements. The Neck Disability Index improved from a preoperative level of $78 \pm 4.47$ to $18 \pm 5.09$ at 6 months, $10 \pm 3.16$ at 12 months, and $1.6 \pm 1.67$ at 2 -year follow-up $(p<0.001)$. All patients achieved a preoperative functional level and could return to their occupation in 3 months. The clinical and radiological outcomes have been outlined in Table 2 .

\section{Discussion}

Most authors have arrived at a common consensus: to treat stable atlas fractures conservatively [8]. Unstable fractures that were initially managed by skeletal traction and a halo vest application have yielded variable outcomes [3]. The complications of prolonged halo application include pin tract infections, pneumonia, and deep vein thrombosis, especially among elderly people [9]. Non-union, persistent articular incongruity resulting in 


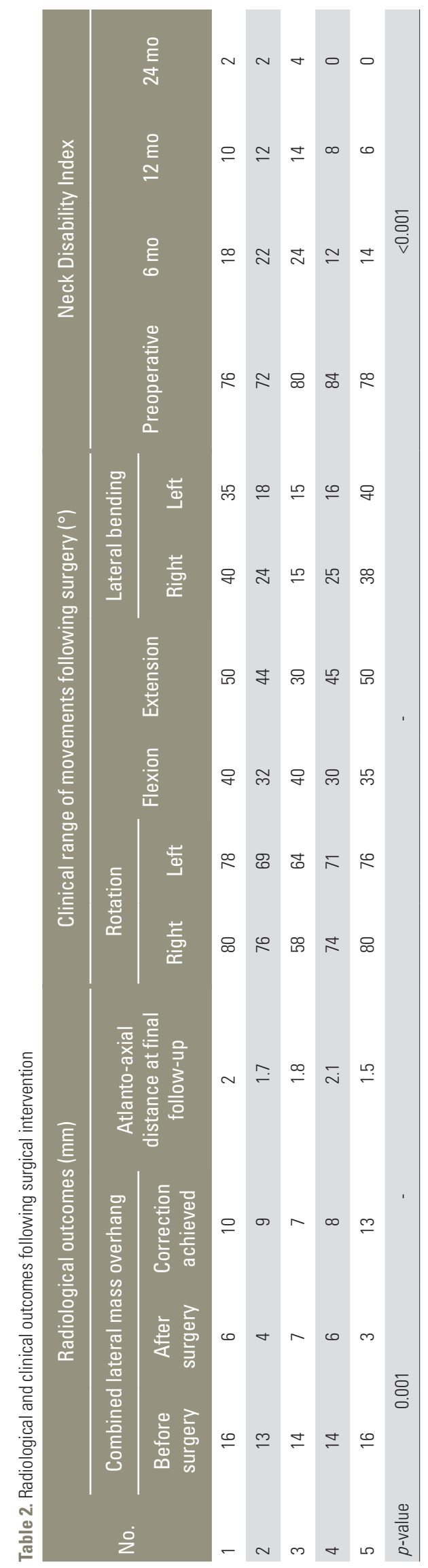

arthritis and pain, cock-robin deformity, and AA instability have also been reported $[9,10]$. Dvorak et al. [3] compared the long-term functional outcomes for various atlas fractures, and noted the inadequate response in unstable injuries managed by the halo vest application. Against this background, many surgeons have suggested performing surgical immobilization in the form of $\mathrm{OC}$ and AA fusion [11]. The efficacy of these procedures in achieving stability is unquestionable. Several modifications to AA fixation have been suggested to improve outcomes [12]. However, in addition to the high morbidity resulting from these complex procedures, they reduce the sagittal and rotational movement by $50 \%$, which has a significant functional and vocational setback [5]. Furthermore, the accelerated subaxial cervical spine degeneration following the fusion of the upper cervical spine has been reported.

The monosegmental fixation of atlas fractures was first performed by Ruf et al. [13] through the trans-oral approach to avoid the fusion of adjacent joints and preserve function in UAF. However, this drew criticism due to the high probability of complications associated with a transoral approach, which include-wound infections and dehiscence, dyspnea, dysphagia, cerebrospinal fluid leaks, meningitis, and velopharyngeal insufficiency [14]. In 2010, Jo et al. [6] circumvented these issues by employing a motion-preserving posterior $\mathrm{C} 1$ lateral mass screw construct, and demonstrated its efficacy at restoring the alignments and achieving bony healing, without evidence of instability. Furthermore, a biomechanical study by Koller et al. [15] evaluated the stability of this novel posterior monosegmental construct under standard physiological loads, and found it to be an effective and valid alternative to AA fusion. However, there is little margin for error in this technique, and the misplacement of screws into the foramen, joints, and canal may cause additional complications in this intricate procedure. Gumpert et al. [7] and Bransford et al. [16] observed the misplacement of the lateral mass screws in monosegmental constructs that required revision surgery. Being a limited osteosynthesis, a successful outcome depends entirely on an adequate hold of the two lateral mass screws, which requires optimal screw trajectories; this becomes challenging, owing to the loss of anatomy and fracture displacement in these UAF $[7,16]$.

In this study, we performed a navigated primary osteosynthesis of these $\mathrm{C} 1$ injuries, which were unstable. The stability of the upper cervical spine primarily depends on 
ligamentous support [17]. The transverse atlantal ligament (TAL) is the primary structural support for the AA joint [17], while additional stabilizers are apical and alar ligaments, which function as a tension band and requires an appropriate $\mathrm{C} 0-\mathrm{C} 2$ height to work. This has been described as the "Buoy phenomenon" by Li et al. [18]. Atlas fractures have been considered unstable based on the rule of Spence et al. [19], which states that there is a high chance of disruption of the TAL, if the sum of the lateral displacement of the mass of $\mathrm{C} 1$ over $\mathrm{C} 2$ exceeds $6.9 \mathrm{~mm}$. Heller et al. [20] modified this value to $8.1 \mathrm{~mm}$ to overcome magnification errors. In our case series, the mean lateral displacement of the lateral mass of $\mathrm{C} 1$ over C2 was $14.6 \pm 1.34 \mathrm{~mm}$, and ranged from 13 to $16 \mathrm{~mm}$, much higher than the cut-off threshold values to consider them as stable. These displacement values are comparable to the preoperative values of $14.6 \mathrm{~mm}$ in the OC fusion group and 12.5 in the AA fusion group in a study that evaluated the outcomes of classical fusion surgeries in UAF [5].

Although the magnetic resonance imaging (MRI) is regarded as the gold standard modality of choice for documenting TAL disruption, the absence of neurological dysfunction or upper motor neuron signs in our series did not warrant an MRI, while a diagnosis of UAF was made based on substantial evidence such as excess lateral mass overhang, an increase in AA distance, and TAL avulsion injuries. Considering the severe displacement in these UAF, a primary internal osteosynthesis was performed, and we subsequently discuss our results and successful management.

One of the primary determinants of a successful outcome in this surgery was to restore $\mathrm{C} 0-\mathrm{C} 2$ height, and this was achieved by a controlled distraction using a Mayfield clamp. The traction also stabilized the longitudinal ligaments, and helped in the reduction of lateral mass over C2. A controlled compression of $\mathrm{C} 1$ will further help in fracture reduction, which requires the placement of $\mathrm{C} 1$ lateral mass screws. Although navigated surgery in degenerative cervical spine surgeries is a well-documented entity with proven outcomes $[21,22]$, there are significant challenges in the installation of $\mathrm{C} 1$ screws in UAF. The accuracy of navigated surgery depends on the maintenance of the immobility of the instrumented spinal column, after completing an ICT scan. In UAF, the lateral mass overhang and disruption of ligaments cause excessive movement while the screws are placed, which might cause wobbling and motion-related artifacts. To overcome these challenges, the head was held in traction before the ICT to stretch the longitudinal ligaments attached to the atlas, which in turn provided stability.

Furthermore, to prevent dangling, entry points in the lateral mass were first created using a high-speed 2-mm Midas Rex Legend motorized burr, and the tract was further deepened with the burr after checking the accuracy of the entry point. The use of a small burr at a high revolution generates more friction, and enables the creation of a path inside the bony cortex, without wobbling the lateral mass. Handheld instruments have to be avoided. The creation of drill trajectories can be performed in two ways. A completely navigated power drill can be used to create the screw trajectory, but as per the author's experience, there is always a movement in $\mathrm{C} 1$ while placing lateral mass screws, especially when the integrity of the arch is lost, as for these UAF. Using a modified technique, we first drilled the screw trajectory in the required path for a depth of 5 $\mathrm{mm}$ only. The accuracy of the navigation was confirmed, the screw trajectory made so far was checked, and the further trajectory then created; and this process was repeated. Minor adjustments in screw trajectories were made as and when required during this continual checking process. The same process had to be repeated on another side before the placement of final screws because inserting the screws on one side before creating a trajectory will cause excess movement in $\mathrm{C} 1$, leading to navigation inaccuracy on the contralateral side. After placing the $\mathrm{C} 1$ screws, care must be taken to apply controlled compression over the $\mathrm{C} 1$ screws because excessive force will result in the opening of fractured anterior ends.

Aside from accuracy, the navigation allows us to perform this surgery more efficiently in terms of blood loss $(84.4 \pm 8 \mathrm{~mL})$ and operating time $(77 \pm 14$ minutes), compared to $650 \mathrm{~mL}$ of blood loss and 110 minutes of operating time in the standard OC and AA fusion [5]. A retrospective analysis of similar non-navigated monosegmental fixation performed in nine patients revealed a blood loss of $106 \mathrm{~mL}$ and an operating time of $127 \mathrm{~min}$ utes, higher than the observed values in our current study [23]. Furthermore, the CLMD/overhang of $\mathrm{C} 1$ over $\mathrm{C} 2$ in our series was $14.6 \pm 1.34 \mathrm{~mm}$, which is a highly unstable $\mathrm{C} 1$ fracture, and represents a TAL injury, compared to only $7 \pm 2.2 \mathrm{~mm}$ in their recent study. Despite the excessive displacement observed in our study, we achieved a significant reduction of the lateral mass.

$\mathrm{Hu}$ et al. [5] performed a retrospective comparative 
analysis of UAF treated by OC fusion (20 patients) and AA fusion (48 patients). In this study, all patients who underwent $\mathrm{OC}$ fusion had severe restrictions in the flexion-extension range of movement, and only $14(70 \%)$ were satisfied with the outcome. Both groups had severe restrictions in rotation at 12 months of follow-up. In our study, all patients subjectively felt that they had been restored to their pre-injury functional status, with no restriction in the range of movements, and were able to perform their occupations as before, as mentioned in Table 1, which requires quite a lot of rotational movements.

A recent systematic review of the literature in non-navigated $\mathrm{C} 1$ solitary fixations evaluated seven clinical studies, and found that three reported screw misplacements [10]. In a case series of three patients with sagittal split unilateral lateral mass fractures who underwent similar $\mathrm{C} 1$ constructs, one patient had a screw placed into the fracture interspace, which required revision [16]. Gumpert et al. [7] noticed the penetration of screws into the spinal canal in one of three patients who underwent $\mathrm{C} 1$ solitary osteosynthesis. Although the biomechanical stability of this construct has been proven, there has been a higher rate of complications in lateral mass screw placement by the freehand technique. The navigated $\mathrm{C} 1$ fixation in these UAF is believed to be an ideal strategy to prevent such cortex violations.

To the best of our knowledge, this is the first-ever case series on the primary AIRO CT navigated limited osteosynthesis of UAF. The navigation allowed us to place the lateral mass screws in the best possible biomechanically sound trajectory, which then permitted fracture reduction and maintenance through controlled compression across the fixation. The follow-up CT showed adequate healing, and a significant decrease in CLMD. There were no complications or evidence of AA instability. The goals of our surgical intervention were to restore alignment and reasonable anatomy to allow for the physiological healing of the TAL and $\mathrm{C} 1$ fracture, with the objective of attaining stability and retaining mobility to achieve excellent clinical, radiological, and functional outcomes.

This technique of fixation can be successfully performed in unstable burst fractures; however, it should be used with caution in patients with comminuted lateral mass fractures because the stability of this fixation primary depends on an adequate hold over the lateral mass [4]. It is practically difficult, though not impossible, to instrument $\mathrm{C} 1$ if there is excessive displacement of the lateral mass in a four-part fracture with comminution, and this fixation might not be the solution to all Jefferson fractures. The biomechanical stability of this construct has been proven under standard physiological loads; however, it is contraindicated in $\mathrm{AO}$ dislocations. In this case series, there were no instances of lateral mass comminution or associated injuries. Knowledge of the factors that may contribute to navigation inaccuracies is also essential to perform this minimally invasive $\mathrm{C} 1$ osteosynthesis.

\section{Conclusions}

$\mathrm{AO}$ and AA junction stability depends mainly on ligamentous structures, which work as a tension band only when $\mathrm{C} 0-\mathrm{C} 2$ height is maintained. Further stability is provided by the congruent articular integrity, which is bound to fail mechanically when the axial compressive load is applied, as it occurs in UAF. There is growing evidence to support a limited internal fixation for atlas through both anterior and posterior approaches in such injuries, which helps in restoring the alignment, potentiating the healing of such injuries, and preventing instability, while retaining movement of the OC and AA joints. The margin for error in such intricate fixations is very minimal, and the efficacy of construct primarily depends on two screws, which gives the surgeon only one chance to drill appropriate screw trajectories. The malposition of screws in the fracture interspace, foramen, and joint space has been reported and requires revision surgery. A navigated $\mathrm{C} 1$ lateral mass screw fixation can negate such complications and permit accurate and adequate fixation in such challenging situations.

\section{Conflict of Interest}

No potential conflict of interest relevant to this article was reported.

\section{Funding}

The project was funded by Ganga Orthopaedic Research \& Education Foundation, Coimbatore, India (Grant no., GOREF-01-2015).

\section{References}

1. An HS. Cervical spine trauma. Spine (Phila Pa 1976) 
$1998 ; 23: 2713-29$

2. Ryan MD, Henderson JJ. The epidemiology of fractures and fracture-dislocations of the cervical spine. Injury 1992;23:38-40.

3. Dvorak MF, Johnson MG, Boyd M, Johnson G, Kwon BK, Fisher CG. Long-term health-related quality of life outcomes following Jefferson-type burst fractures of the atlas. J Neurosurg Spine 2005;2:411-7.

4. Kandziora F, Scholz M, Pingel A, et al. Treatment of atlas fractures: recommendations of the Spine Section of the German Society for Orthopaedics and Trauma (DGOU). Global Spine J 2018 Sep;8(2 Suppl):5S-11S.

5. Hu Y, Yuan ZS, Kepler CK, Dong WX, Sun XY, Zhang J. Comparison of occipitocervical and atlantoaxial fusion in treatment of unstable Jefferson fractures. Indian J Orthop 2017;51:28-35.

6. Jo KW, Park IS, Hong JT. Motion-preserving reduction and fixation of $\mathrm{C} 1$ Jefferson fracture using a C1 lateral mass screw construct. J Clin Neurosci 2011;18:695-8.

7. Gumpert R, Poglitsch T, Krassnig R, Pranzl R, Puchwein P. Reduction and ring fixation of instable $\mathrm{C} 1$ fractures with monoaxial pedicle screws. Arch Orthop Trauma Surg 2017;137:1253-9.

8. Ryken TC, Aarabi B, Dhall SS, et al. Management of isolated fractures of the atlas in adults. Neurosurgery 2013;72 Suppl 2:127-31.

9. Horn EM, Theodore N, Feiz-Erfan I, Lekovic GP, Dickman CA, Sonntag VK. Complications of halo fixation in the elderly. J Neurosurg Spine 2006;5:46-9.

10. Bednar DA, Almansoori KA. Solitary C1 posterior fixation for unstable isolated atlas fractures: case report and systematic review of the literature. Global Spine J 2016;6:375-82.

11. Hein C, Richter HP, Rath SA. Atlantoaxial screw fixation for the treatment of isolated and combined unstable Jefferson fractures: experiences with 8 patients. Acta Neurochir (Wien) 2002;144:1187-92.

12. Mummaneni PV, Haid RW. Atlantoaxial fixation: overview of all techniques. Neurol India 2005;53:40815.
13. Ruf M, Melcher R, Harms J. Transoral reduction and osteosynthesis $\mathrm{C} 1$ as a function-preserving option in the treatment of unstable Jefferson fractures. Spine (Phila Pa 1976) 2004;29:823-7.

14. Kingdom TT, Nockels RP, Kaplan MJ. Transoraltranspharyngeal approach to the craniocervical junction. Otolaryngol Head Neck Surg 1995;113:393-400.

15. Koller H, Resch H, Tauber M, et al. A biomechanical rationale for $\mathrm{C} 1$-ring osteosynthesis as treatment for displaced Jefferson burst fractures with incompetency of the transverse atlantal ligament. Eur Spine J 2010;19:1288-98.

16. Bransford R, Chapman JR, Bellabarba C. Primary internal fixation of unilateral C1 lateral mass sagittal split fractures: a series of 3 cases. J Spinal Disord Tech 2011;24:157-63.

17. Oda T, Panjabi MM, Crisco JJ 3rd, Oxland TR, Katz L, Nolte LP. Experimental study of atlas injuries. II. Relevance to clinical diagnosis and treatment. Spine (Phila Pa 1976) 1991;16(10 Suppl):S466-73.

18. Li L, Teng H, Pan J, et al. Direct posterior c1 lateral mass screws compression reduction and osteosynthesis in the treatment of unstable Jefferson fractures. Spine (Phila Pa 1976) 2011;36:E1046-51.

19. Spence KF Jr, Decker S, Sell KW. Bursting atlantal fracture associated with rupture of the transverse ligament. J Bone Joint Surg Am 1970;52:543-9.

20. Heller JG, Viroslav S, Hudson T. Jefferson fractures: the role of magnification artifact in assessing transverse ligament integrity. J Spinal Disord 1993;6:3926.

21. Hecht N, Kamphuis M, Czabanka M, et al. Accuracy and workflow of navigated spinal instrumentation with the mobile AIRO(R) CT scanner. Eur Spine J 2016;25:716-23.

22. Czabanka M, Haemmerli J, Hecht N, et al. Spinal navigation for posterior instrumentation of C1-2 instability using a mobile intraoperative CT scanner. J Neurosurg Spine 2017;27:268-75.

23. Zhang YS, Zhang JX, Yang QG, Li W, Tao H, Shen CL. Posterior osteosynthesis with monoaxial lateral mass screw-rod system for unstable $\mathrm{C} 1$ burst fractures. Spine J 2018;18:107-14. 